\title{
Time evolution of the South Atlantic Magnetic Anomaly
}

\author{
GELVAM A. HARTMANN and IGOR G. PACCA \\ Departamento de Geofísica, Instituto de Astronomia, Geofísica e Ciências Atmosféricas \\ Universidade de São Paulo, Rua do Matão, 1226, Cidade Universitária \\ 05508-090 São Paulo, SP, Brasil \\ Manuscript received on October 22, 2007; accepted for publication on March 26, 2009; \\ contributed by IGOR G. PACCA*
}

\begin{abstract}
The South Atlantic Magnetic Anomaly (SAMA) is one of the most outstanding anomalies of the geomagnetic field. The SAMA secular variation was obtained and compared to the evolution of other anomalies using spherical harmonic field models for the 1590-2005 period. An analysis of data from four South American observatories shows how this large scale anomaly affected their measurements. Since SAMA is a low total field anomaly, the field was separated into its non-dipolar, quadrupolar and octupolar parts. The time evolution of the non-dipole/total, quadrupolar/total and octupolar/total field ratios yielded increasingly high values for the South Atlantic since 1750. The SAMA evolution is compared to the evolution of other large scale surface geomagnetic features like the North and the South Pole and the Siberia High, and this comparison shows the intensity equilibrium between these anomalies in both hemispheres. The analysis of non-dipole fields in historical period suggests that SAMA is governed by (i) quadrupolar field for drift, and (ii) quadrupolar and octupolar fields for intensity and area of influence. Furthermore, our study reinforces the possibility that SAMA may be related to reverse fluxes in the outer core under the South Atlantic region.
\end{abstract}

Key words: geomagnetic field, non-dipole field anomalies, secular variation, South Atlantic Magnetic Anomaly.

\section{INTRODUCTION}

The morphology and time variation of the geomagnetic field result from magnetohydrodynamic processes that take place in the Earth's outer core. The study of the main characteristics of the field observed at the Earth's surface, together with their variations in historical and geological time scales, has enabled the elaboration of numerical geodynamo simulations that have been successful in providing explanations for features of the field such as its predominantly dipolar character, secular variation and field reversals (e.g. Glatzmaier and Roberts 1995a, b, Kageyama et al. 1995, Kageyama and Sato 1997, Kuang and Bloxham 1999). The results of geodynamo models are compared with the inversion of the

\footnotetext{
* Member Academia Brasileira de Ciências Correspondence to: Gelvam A. Hartmann

E-mail: gelvam@iag.usp.br; gelvam@gmail.com
}

geomagnetic field data at the core-mantle boundary (CMB) (e.g. Roberts and Glatzmaier 2000).

After field intensity measurements started around 1840, data show more details of the geomagnetic field in comparison with direction data only (e.g. Chapman and Bartels 1940). The South Atlantic Magnetic Anomaly (SAMA), where the total field intensity is unusually low, is one of the most outstanding features of the geomagnetic field, presently occupying the area between South America and South Africa. In general, SAMA shows a westward drift, and predictions of its variations have been made based on a linear extrapolation (Heirtzler 2002), but they are rather approximate and do not reflect the current configuration of the geomagnetic field. The SAMA area of influence coincides with a region in space of intensive radiation close to Earth. This happens because the low SAMA magnetic fields enable the 
entrance of high energy particles in the magnetosphere (Heynderickx 1996, Heirtzler 2002). This increase of cosmic ray particles may affect objects that orbit Earth such as satellites and space stations (e.g. Badhwar 1997, Buhler et al. 2002, Badhwar et al. 2002, Barde et al. 2002, Willis et al. 2004). These effects may be detected also on the surface of Earth as disturbances in communications and induced currents in pipelines and transmission lines (Padilha 1995, Pinto et al. 2004, Trivedi et al. 2005). These SAMA effects have also been the object of space geophysics research (Pinto Jr and Gonzalez 1986, 1989, Pinto Jr et al. 1989, 1990, 1992, 1997 , Fiandrini et al. 2004), in the study of trapped electrons in radiation belts.

Some authors have related SAMA to the Northern-Southern hemisphere asymmetry of the geomagnetic field (Fraser-Smith 1987, Pinto Jr et al. 1992, Heynderickx 1996, Heirtzler 2002). The eccentric dipole that best represents the geomagnetic field is displaced from the Earth's center towards Northwestern Pacific $\left(21.47^{\circ} \mathrm{N} ; 144.77^{\circ} \mathrm{E}\right)$ (Fraser-Smith 1987). The antipodal point would then be in the Southern Atlantic, but rather far from the SAMA center. However, the SAMA behavior may indicate that these asymmetries may be connected to the general decrease of the dipolar field and to the significant increase of the non-dipolar field in the Southern Atlantic (e.g. Bloxham et al. 1989, Bloxham and Jackson 1992, Hulot et al. 2002, Olson 2002, Pacca and Hartmann 2005, G.A. Hartmann, unpublished data ${ }^{1}$ ). Another remarkable feature of the geomagnetic field is the Siberia High, a region where field intensities are considerably higher than those for comparable latitudes. This anomaly, SAMA and the geomagnetic poles are the most important features of the geomagnetic field, and their investigation and comparison to each other can provide important information on the dynamics of the geomagnetic field.

Using spherical harmonics field models, such as those obtained by Jackson et al. (2000) for the historical period (1590-1990) (called GUFM1) and the IGRF (International Geomagnetic Reference Field) and DGRF (Definitive Geomagnetic Reference Field) models for the past century, the main characteristics of the field secular variation are compared to SAMA. We also

\footnotetext{
${ }^{1}$ Online version: http://www.teses.usp.br/
}

show how the SAMA variation affected measurements of four South American observatories, the non-dipolar source character of the South Atlantic magnetic field, and the relation between SAMA and other geomagnetic anomalies. This analysis of the geomagnetic field may be able to lead to helpful links for discussing field generation processes in the CMB. The essential contents of this article were part of a MSc. Dissertation presented at the University of São Paulo (G.A. Hartmann, unpublished data ${ }^{1}$ ).

\section{LOCATION DETERMINATION FOR SAMA AND OTHER ANOMALIES}

The time and space variation of SAMA depends on the morphological behavior of the whole field. The SAMA center has been taken as the locus of minimum intensity in the South Atlantic, as proposed by Heynderickx (1996). A similar procedure was used to define the center of other anomalies like the North Pole (NP), the South Pole (SP) and the Siberia High (SH) as the maximum global intensities in a region. The center of nondipole anomalies has also been taken as points of maximum/minimum intensity. These anomaly centers are computed from spherical harmonic expansions of the geomagnetic potential, i.e. geomagnetic field models. The field models used in this study are DGRF, IGRF and GUFM1. DGRF and IGRF models provide sets of Gauss coefficients up to spherical harmonic degree $n=m=10$ (or 13, for IGRF 2000 onwards) and GUFM1 up to $n=m=14$. Components $X, Y$ and $Z$ of the geomagnetic field can be expressed as functions of time $(t)$ and spherical coordinates $(r, \theta, \lambda)$ by:

$$
\begin{aligned}
X(r, \theta, \lambda, t)= & \sum_{n=1}^{\infty} \sum_{m=0}^{m}\left[g_{n}^{m}(t) \cos m \lambda\right. \\
& \left.+h_{n}^{m}(t) \sin m \lambda\right] \frac{d P_{n}^{m}(\theta)}{d \theta}\left(\frac{a}{r}\right)^{n+2} \\
Y(r, \theta, \lambda, t)= & \frac{1}{\sin \theta} \sum_{n=1}^{\infty} \sum_{m=0}^{m}\left[m g_{n}^{m}(t) \sin m \lambda\right. \\
& \left.+m h_{n}^{m}(t) \cos m \lambda\right] P_{n}^{m}(\theta)\left(\frac{a}{r}\right)^{n+2} \\
Z(r, \theta, \lambda, t)= & \sum_{n=1}^{\infty} \sum_{m=0}^{m}\left\{g_{n}^{m}(t) \cos m \lambda\right. \\
& \left.+h_{n}^{m}(t) \sin m \lambda\right\} P_{n}^{m}(\theta)\left(\frac{a}{r}\right)^{n+2}
\end{aligned}
$$




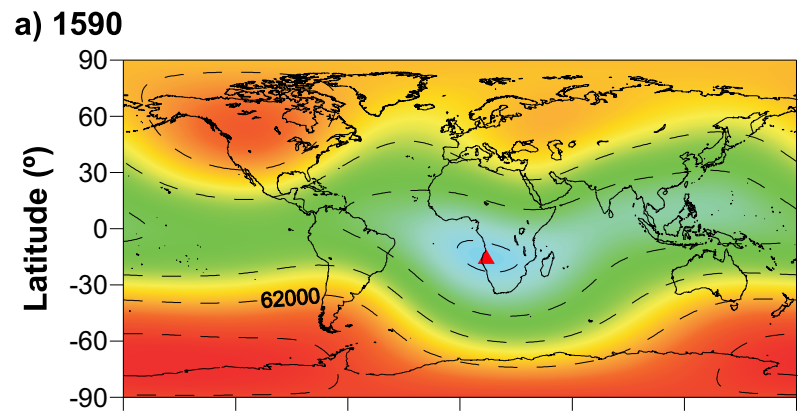

c) 1790

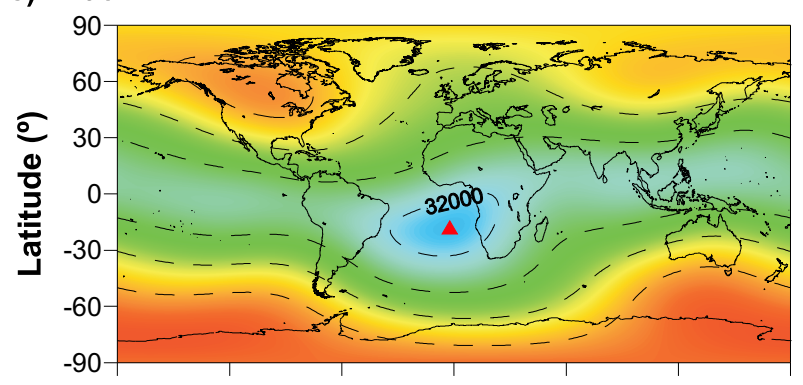

e) 1950

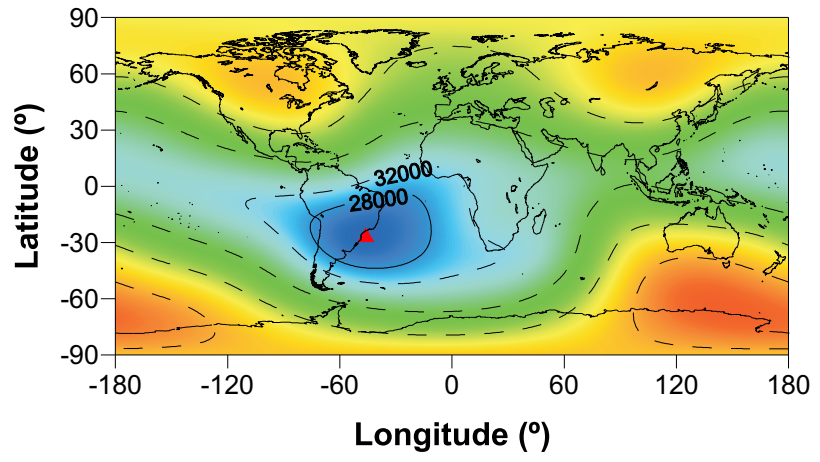

b) $\mathbf{1 6 9 0}$

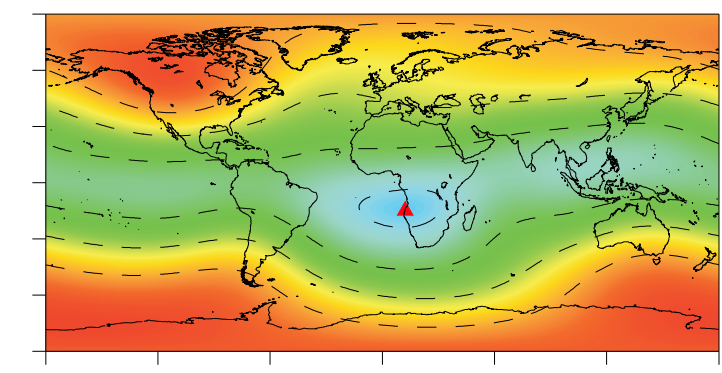

d) 1890

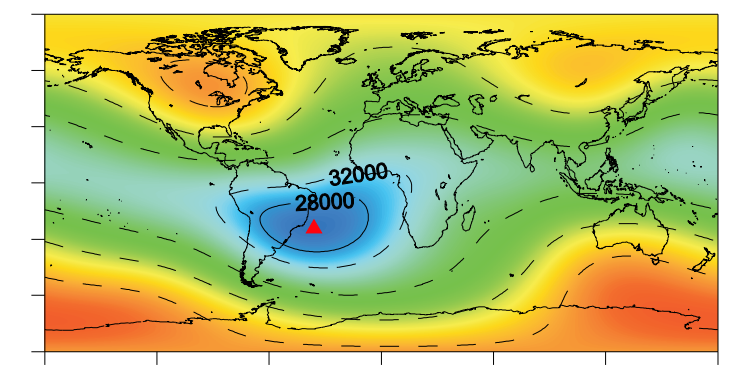

f) 2005

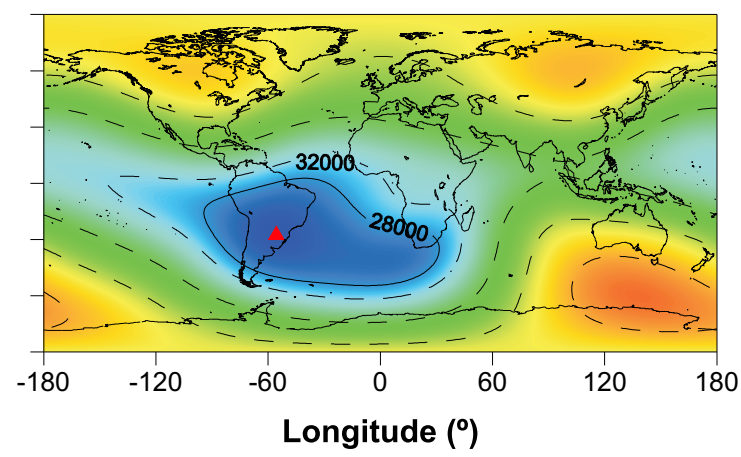

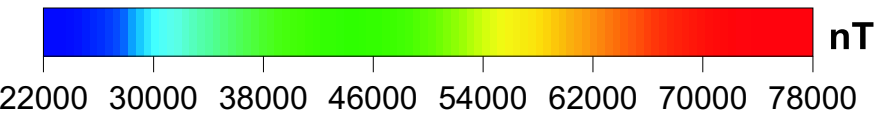

Fig. 1 - Examples of geomagnetic field total intensity maps obtained with GUFM1 and IGRF models. The red triangle indicates the SAMA center, and the 28000nT contours shows the SAMA range influence area.

where $a$ is Earth's mean radius $(6371.2 \mathrm{~km}) . P_{n}^{m}(\theta)$ is associate Legendre polynomials and $g_{n}^{m}(t)$ and $h_{n}^{m}(t)$ are field models Gauss coefficients (e.g. Langel 1987).

And the total field will be:

$$
B=\left(X^{2}+Y^{2}+Z^{2}\right)^{1 / 2}
$$

The resolution of maximum/minimum intensity points location will depend on the resolution of the spherical harmonic models that are used. The contributions of non-dipolar $(n>1)$, quadrupolar $(n=2)$ and octupolar $(n=3)$ fields have also been calculated in an attempt to characterize the SAMA signatures (Section non-dipolar field and Fig. 6).

\section{SAMA: THE MAIN FEATURES AND TIME-EVOLUTION}

The Anomaly Center And its Path

Intensity variations for the past 415 years display the behavior of outstanding geomagnetic features like SAMA, NP, SP and SH. The maps and plots using 
GUFM1 models prior to 1840 involve an approximation to determine the magnitude of $B$. These models assume that $g_{1}^{0}$ was decreasing at a rate of $15 \mathrm{nT} / \mathrm{year}$ prior to 1840 . This assumption was necessary because direct absolute intensity measurements were not available for the time before 1840 (e.g. Barraclough 1974, Jackson et al. 2000). Nevertheless, it is possible to analyze the main characteristics of the geomagnetic field morphology. Some examples of total intensity plots obtained with field models are shown in Figure 1. Time and space variations of SAMA follow in part the morphological behavior of the field in general.

Figure 2a shows the drift of the SAMA center for the past 415 years in five year intervals. For this period, SAMA shows a westward drift of $70^{\circ}\left(\approx 0.17^{\circ} /\right.$ year $)$ and a southward drift of $12^{\circ}\left(\approx 0.03^{\circ}\right.$ year $)$. The whole interval may be divided into three sectors:

(i) $1590-1750$, when SAMA presented variations of $\approx 6^{\circ}$ in longitude and $\approx 1.5^{\circ}$ in latitude;

(ii) 1750 to $1945-1950$, when both westward and southward drifts were approximately constant, and

(iii) 1945-2005, when latitude variation was much smaller and practically there was only a westward drift.

Therefore SAMA shows a general westward drift, but with different rates for certain intervals such as those before and after 1750 .

For the past 105 years GUFM1 can be compared to IGRF models. Figure $2 \mathrm{~b}$ shows a second diagram of the SAMA space variation where four South American observatories that are located near to its center are indicated. For the past century the SAMA southern displacement can be separated into two intervals. After 1945-1950, the latitude variation was much smaller than that for the previous period between 1900-1945. The mean variation rate for the past 60 years was very small, practically without a change in latitude. The westward drift rates obtained with particle fluxes (Badhwar 1997, 2002, Buhler et al. 2002) are approximately $0.1^{\circ}$ \% year higher than the ones obtained with the minimum field for the past 105 years. The particle flux data indicate a northern displacement while the minimum field indicates a southern displacement.

\section{INTENSITY}

The SAMA center intensity changes with variable rates for different time intervals. Figure 3 shows the SAMA intensity variation for the past 415 years. During this interval, the SAMA intensity decreased about 8500nT, with an average decrease of $22.7 \mathrm{nT} /$ year. Intensity variations (intensity first derivatives) are presented in Figure 3 and in Table I. Between 1590-1750, intensity variations were rather low when compared to higher values after this interval. Figure 3 shows variations up to $-65 \mathrm{nT} /$ year between 1850-1900, that seem to be meaningful for a low latitude anomaly.

TABLE I

Intensity variation (nT/year) at the SAMA, SH, NP and $S P$ center for the past 415 years.

\begin{tabular}{c|c|c|c|c}
\hline GUFM1 Interval & SAMA & SH & NP & SP \\
\hline $1590-1640$ & -3.7 & - & 33.5 & -63.1 \\
\hline $1640-1690$ & -7.4 & - & 2.6 & -17.2 \\
\hline $1690-1740$ & -3.9 & - & -65.6 & -12.1 \\
\hline $1740-1790$ & -17.8 & $-27.4^{*}$ & -51.7 & -31.4 \\
\hline $1790-1840$ & -30.4 & -20.8 & -7.6 & -8.1 \\
\hline $1840-1890$ & -48.5 & 19.4 & -5.2 & -5.5 \\
\hline $1890-1940$ & -14.3 & 2.8 & -55.7 & -7.9 \\
\hline $1940-1990$ & -34.6 & 14.9 & -12.3 & -21.9 \\
\hline Mean (nT/year) & $-\mathbf{2 0 . 1}$ & $-\mathbf{2 . 2}$ & $-\mathbf{2 0 . 3}$ & $\mathbf{- 2 0 . 9}$ \\
\hline IGRF Interval & & & & \\
\hline $1900-1950$ & -18.6 & -1.1 & -60.1 & -7 \\
\hline $1950-2005$ & -32 & 2.2 & -28 & -34.7 \\
\hline Mean (nT/year) & $-\mathbf{2 5 . 3}$ & $\mathbf{0 . 5}$ & $-\mathbf{4 4}$ & $\mathbf{- 2 0 . 8}$ \\
\hline \multicolumn{5}{|l}{}
\end{tabular}

*Variation for period between 1770 to 1790.

The SAMA effect is visible in some geomagnetic observatories intensity data. The Vassouras (VSS: $\left.22^{\circ} 24^{\prime} \mathrm{S}, 43^{\circ} 39^{\prime} \mathrm{W}\right)$ observatory in Brazil and Pilar (PIL: $31^{\circ} 39^{\prime} \mathrm{S}, 63^{\circ} 52^{\prime} \mathrm{W}$ ), Las Acacias (LAS: $35^{\circ} \mathrm{S}$, $57^{\circ} 42^{\prime} \mathrm{W}$ ) and La Quiaca (LQA: $22^{\circ} 36^{\prime} \mathrm{S}, 65^{\circ} 36^{\prime} \mathrm{W}$ ) in Argentina show data where the SAMA influence is apparent. The location of these observatories is shown in Figure 2b. Figure 4 shows the total field annual means for these observatories. It is apparent that SAMA causes a decrease in field intensity when it approaches the observatories. The beginning of the Vassouras operation coincides with the period when the SAMA center was approaching it and this corresponds to the highest variations recorded by this observatory. VSS and LQA show 
a)
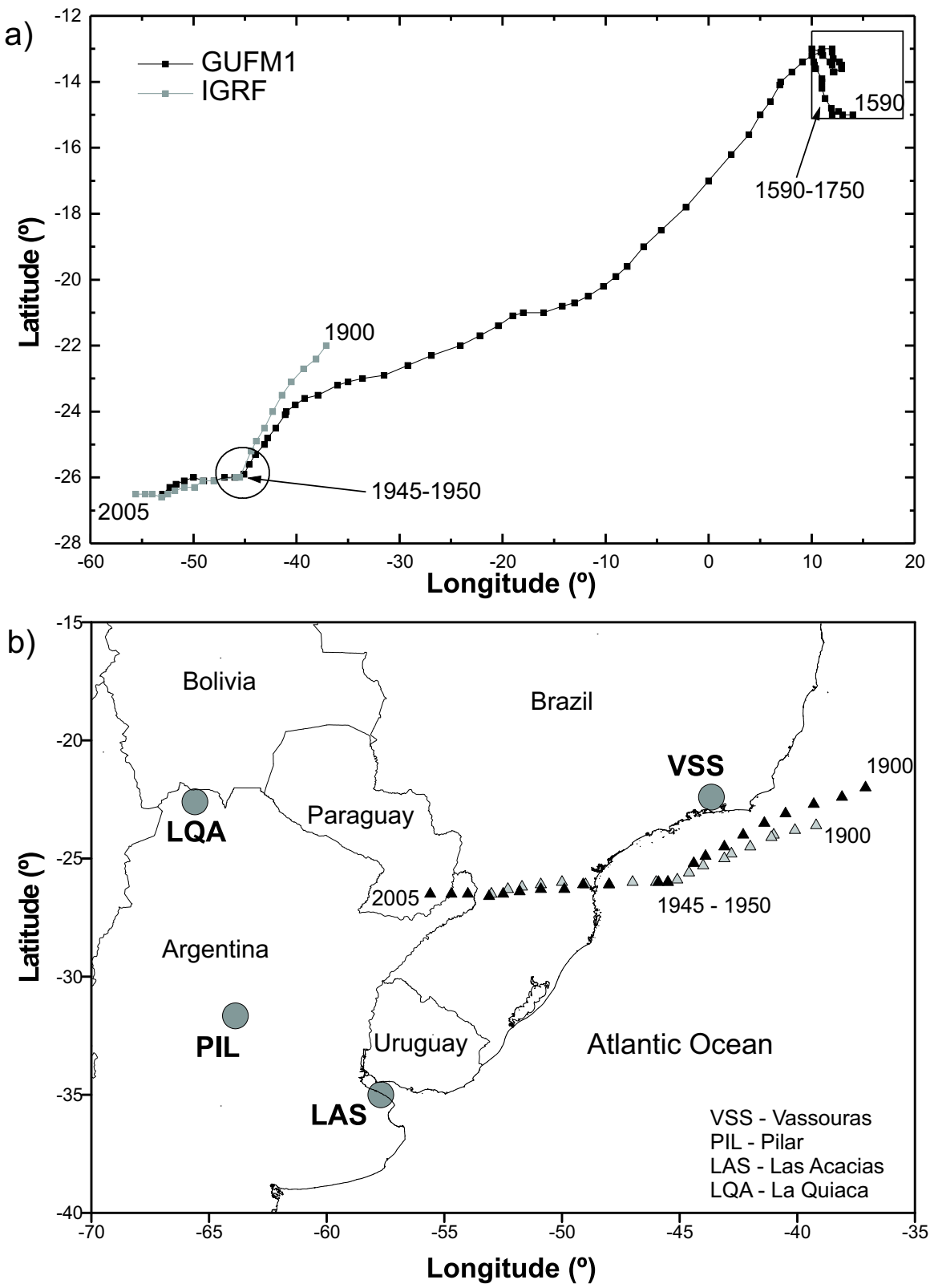

Fig. 2 - (a) the SAMA center trajectory from 1590 to 2005. Note that the 1590-1750 interval corresponds to lower drift rates; (b) the SAMA center trajectory from 1900 to 2005 in relation to the location of four South American Geomagnetic Observatories: Vassouras (VSS) in Brazil, and Las Acacias (LAS), La Quiaca (LQA) and Pilar (PIL), in Argentina.

high variation for 1945-1950, but there is not much variation for PIL. This period is critical because it corresponds to the SAMA center change in trajectory.

Between 1915 and 1940, the SAMA center was approaching VSS, reaching a minimum distance of less than $500 \mathrm{~km}$. The center is presently in an approximately equidistant position from the four observatories. For this period, intensities for the observatories continously decrease even when the distance of the SAMA center with respect to these observatories increases. However, the SAMA area of influence increases as is evident from the 28000 nT contours on the maps of Figure 1; this is undoubtedly an effect of SAMA on the measurements of the observatories. 


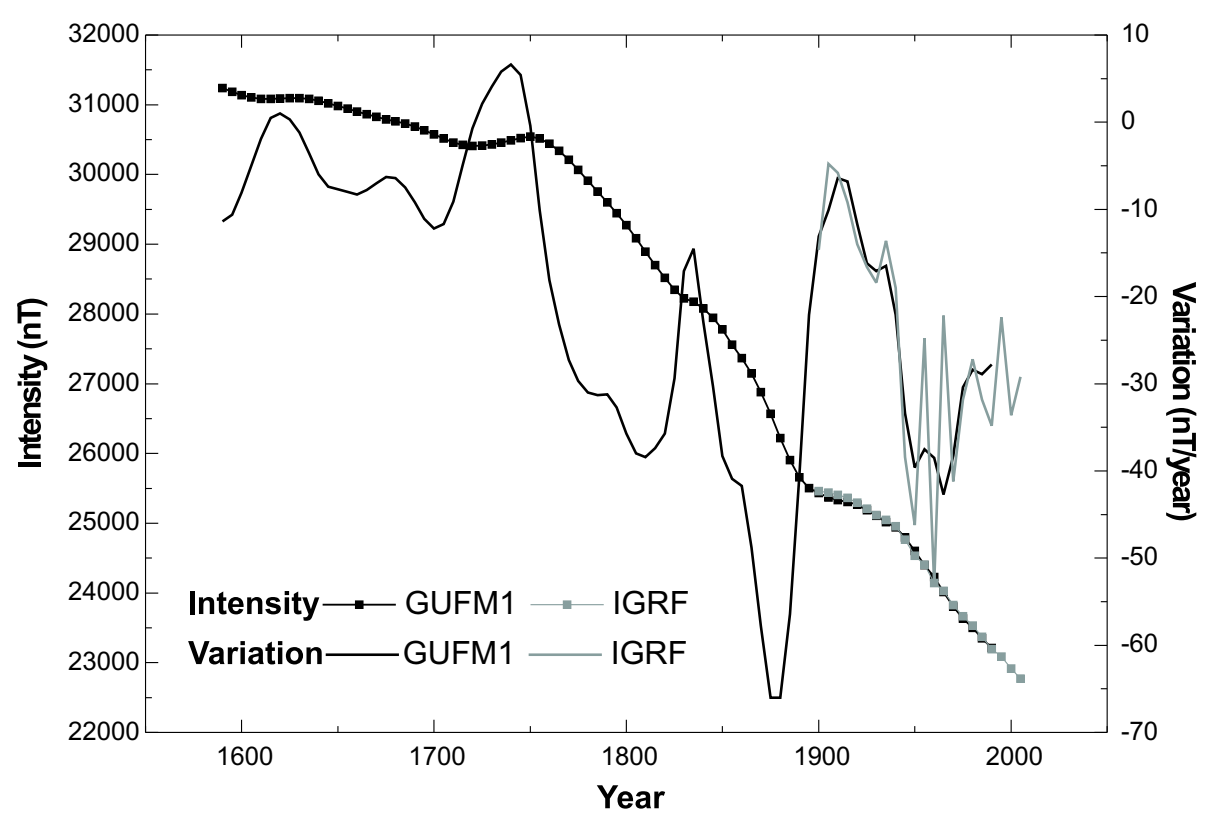

Fig. 3 - Total field intensity variation at the SAMA center for the past 415 years. The left ordinates correspond to total intensity and the right ordinates the first derivative of total intensity.

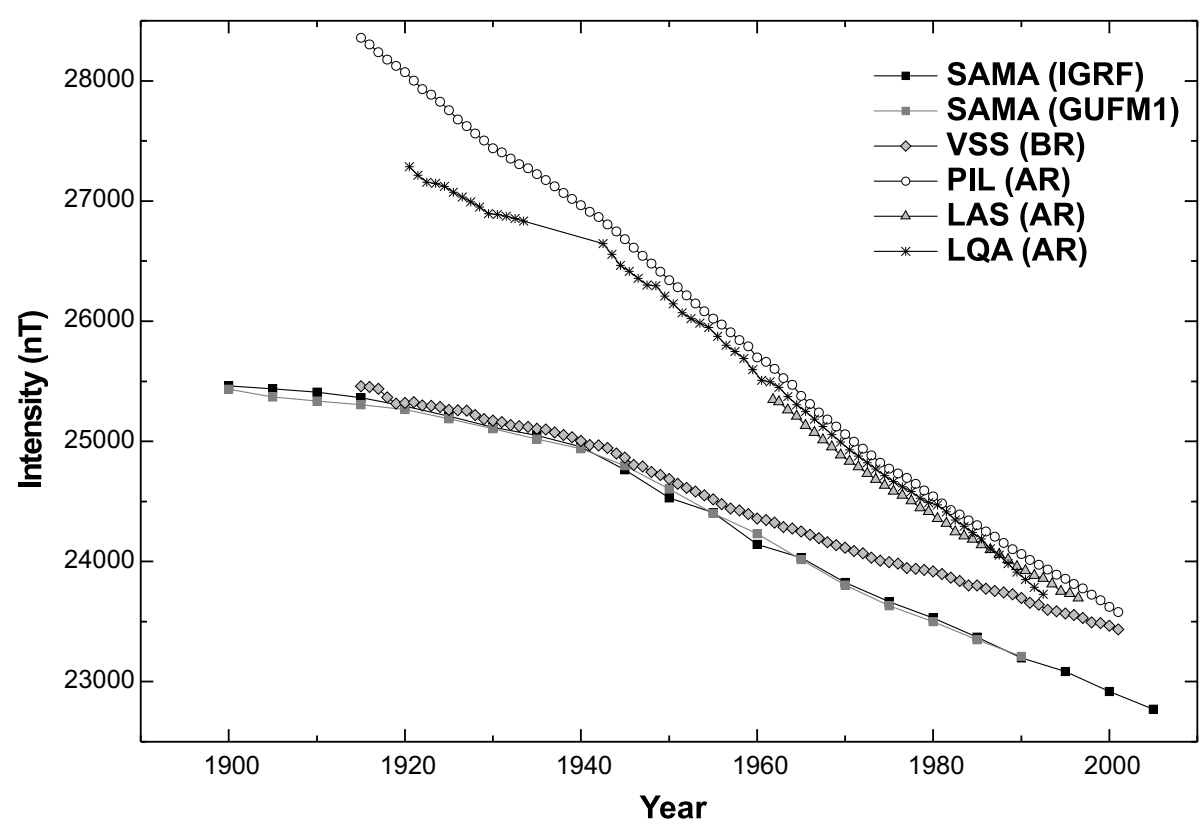

Fig. 4 - Total field intensity variations for the VSS, PIL, LAS, and LQA Observatories.

\section{NON-DIPOLAR FIELD}

The non-dipole field has been increasing with time for the past century and since SAMA is a low total field anomaly, considering the four parts (total, non-dipolar, quadrupolar and octupolar) of the field separately may disclose useful information. Figure 5 shows examples of the maps with the ratio of non-dipole to total field where the main non-dipole contributions to the total field are shown geographically. The maximum values are in- 
a) 1590

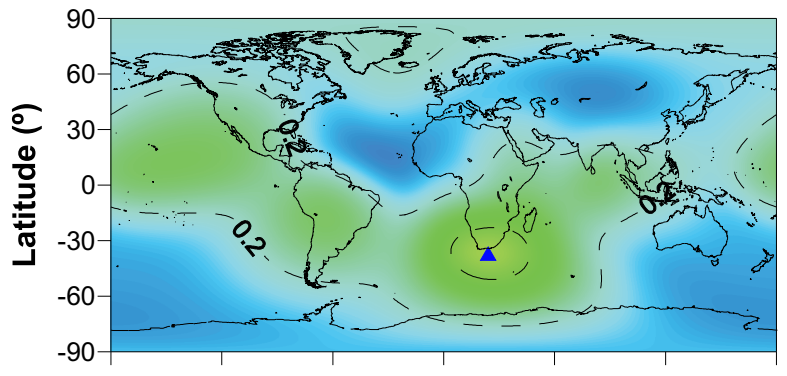

c) 1790

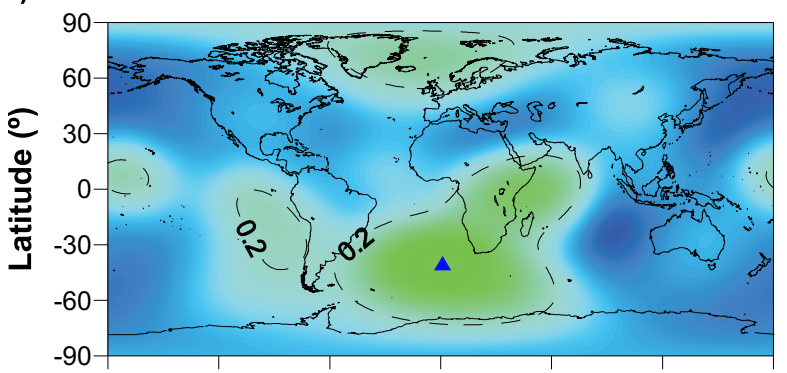

e) 1950

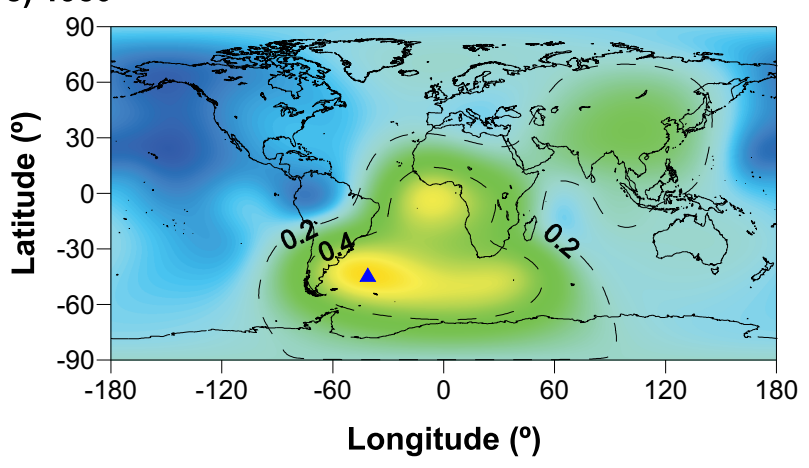

b) 1690

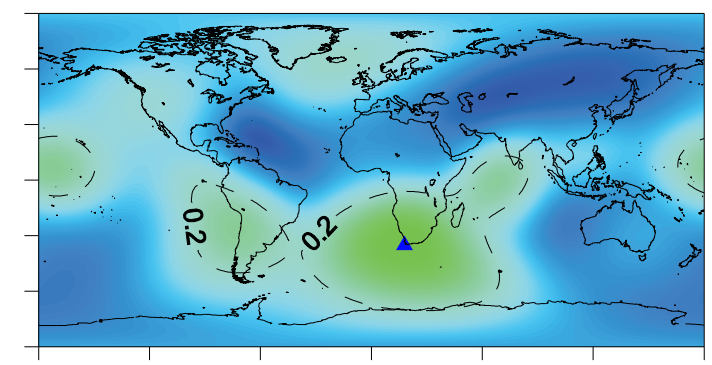

d) 1890

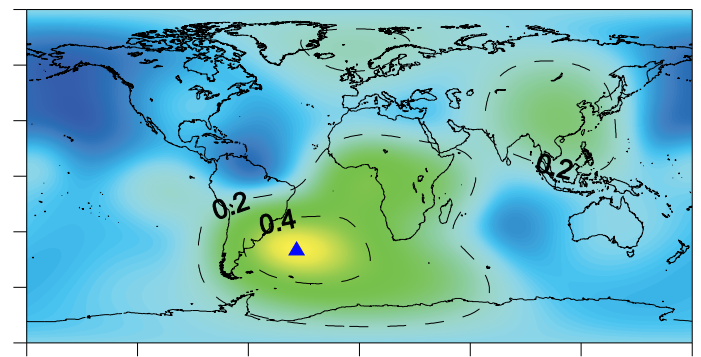

f) 2005

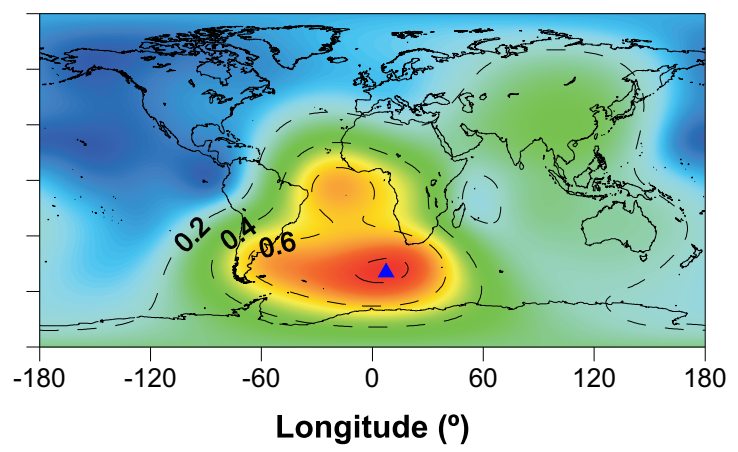

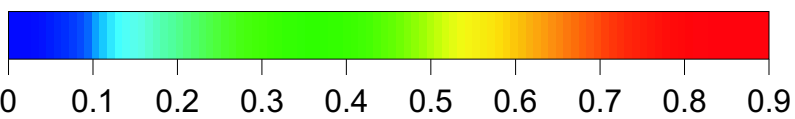

Fig. 5 - The non-dipole/total (NPT) field ratio, showing the drift of the non-dipole field anomaly presently in the South Atlantic. Note the increase in intensity and influence area of the non-dipole field.

dicated by blue triangles and they have been obtained for twenty year intervals for the past 415 years. A similar procedure was used for obtaining the quadrupole and octupole contributions.

Figure 6a shows time variation ratios for the summation of coefficients for non-dipolar/total (NPT), quadrupolar/total (QPT) and octupolar/total (OPT). The left side values correspond to the ratios of the models coefficients, while the right side values correspond to the maximum anomalies in the South Atlantic. The nondipole part of the global field is presently about $17 \%$ of the total field. However, in the past century, the non dipole part increased about $5 \%$, whereas the dipole field decreased also $5 \%$. After $\approx 1750$ the quadrupolar and octupolar sources increase significantly. As shown in the maps of Figure 5, the main non-dipolar sources are in the southern hemisphere, mainly in the South Atlantic, and the maxima associated to these sources are fairly high. The non-dipole maximum contribution presently reaches about $85 \%$ of the total field, and the quadrupole and octupole maximum contributions are respectively $48 \%$ and $40 \%$. 
a)

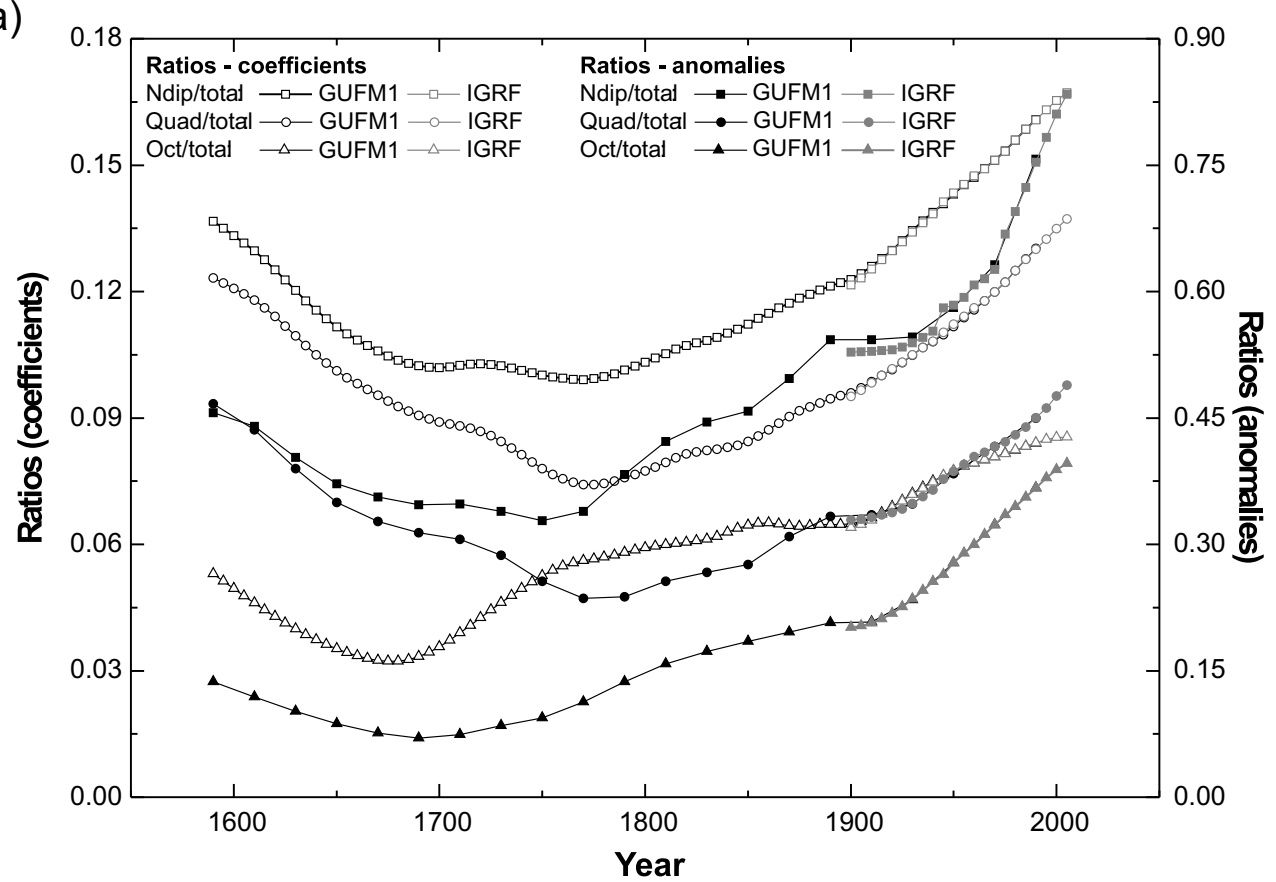

b)

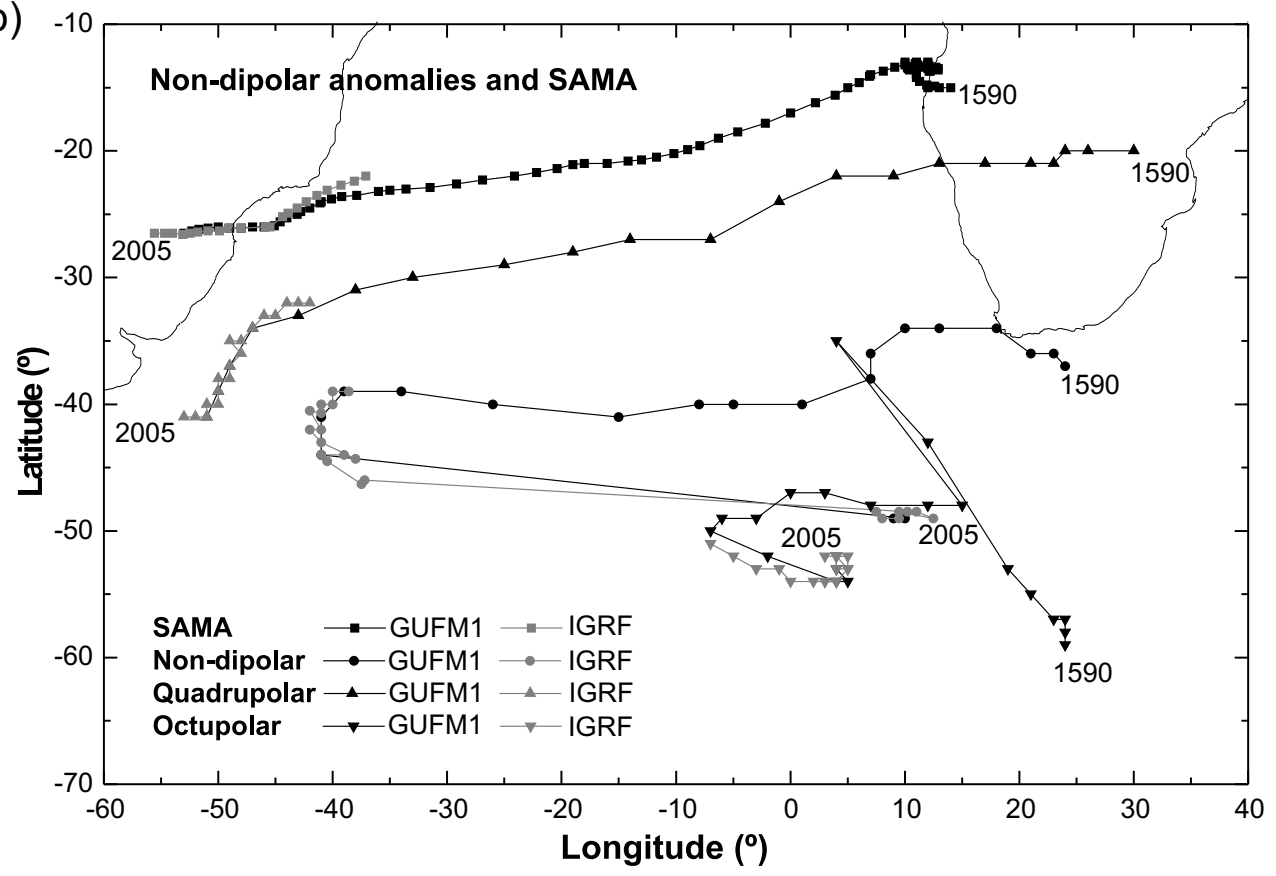

Fig. 6 - Comparison of the non-dipolar contributions. In (a), left: the models coefficients ratios (NPT, QPT and OPT); right: the maximum (anomalies) non-dipole fields (NPT, QPT and OPT). In (b), drifts of the maximum non-dipole fields obtained in (a) and SAMA.

Figure $6 \mathrm{~b}$ compares the drift of these maxima to the SAMA drift. The behavior of NPT and OPT is quite different from that of QPT and SAMA because non-dipole sources do not follow the westward drift systematically.
Yukutake and Tachinaka $(1968,1969)$ distinguish two types of drifts for non-dipole field anomalies: those that show a westward drift and those that are stationary. Some anomalies drift rather randomly, but there is a remark- 
able correlation between the drift of the QPT maximum and that of the SAMA center. From 1750 to present, practically the whole South Atlantic shows high NPT, QPT and OPT ratios, as shown in Figure 6a. Therefore, the high degree terms that correspond to the non-dipole fields have been increasing significantly, indicating the importance of these terms for SAMA.

\section{DISCUSSION}

The main characteristics of the SAMA time and space evolution are a decrease in total geomagnetic field intensity, increase in the influence area and both westward and southward drifts. Secular variation shows that the SAMA morphology is influenced by non-dipole field components. A comparison with the evolution of other large scale anomalies may yield interesting results.

\section{INFLUENCE OF NON-DIPOLE FIELD ON THE SAMA} EVOLUTION

Intensity variations depend strongly on $g_{1}^{0}$. According to some authors, the dipolar core field observed on the surface of the Earth (main field) exceeds the non-dipole field in a time average of a few thousand years, when the axial dipole is predominant (eg. Carlut et al. 1999). According to Olson and Amit (2006), the present dipole decrease could be transient as core fluid motion may reduce the dipole field by transferring energy to other magnetic field harmonics through a turbulent process. This could be inferred from the magnetic flux distribution at the CMB caused by core fluid flow. Non-dipole terms would then fluctuate in a time scale of centuries.

For the historical period, high variation rates of non-dipole sources in the South Atlantic seem to have strong influence on the SAMA behavior, as suggested in the comparison between the drifts of SAMA and that of the quadrupole field anomaly (Fig. 6b). The total intensity of this anomaly during the whole historical period is only a few thousand nT lower than the SAMA intensity. Therefore, the influence of the dipolar field in the SAMA region of influence is small.

Since the non-dipolar time constants are smaller than that of the dipole, energy must be transferred to more than one non-dipole component (Olson and Amit 2006). This would explain the quadrupolar anomaly significant increase in South America as well as that of the octupolar anomaly in Southern Africa and they must influence the SAMA area directly since the $28000 \mathrm{nT}$ contour on the total intensity map for 2005 extends from South America to Southern Africa as shown in Figure 1.

\section{SAMA AND Other Geomagnetic Field Anomalies}

The geomagnetic field morphology is important for the SAMA evolution. Therefore, SAMA is compared to other large scale geomagnetic anomalies, like the SH, NP and SP. Figure 7 shows field intensity variations at the focus of isolines corresponding to SAMA, $\mathrm{SH}, \mathrm{NP}$, and SP for the period between 1590-2005. At first, there seems to be no direct connection among these variations. The NP intensities are lower than those of the SP. However, both poles show a decrease in their intensities. Table I shows the variation rates for the four anomalies, and the data indicate a higher variation for NP. It can also be noted that the addition of SP and SAMA mean variations indicates values that are similar to those corresponding to the summation of NP and $\mathrm{SH}$ mean variations. This may be interpreted as a consequence of the Alfven theorem (Bondi and Gold 1950, Jackson 2003) that states that the total magnetic flux across a spherical surface is invariable. Fluxes in both hemispheres must be conserved, which may mean that intensities in the southern hemisphere may result from the balance between SAMA and SP, while in the northern hemisphere the balance is between NP and SH.

SAMA also shows a decreasing intensity for the past 250 years, but the contribution of the non-dipole field has been important for its region of influence. From 1590 to 1750 , the total field intensities were approximately stable, while the non-dipole field was decreasing. From 1750 onwards, total intensities decrease while the non-dipole field increases.

SH is a high intensity field anomaly, and it becomes evident in total field maps after 1770 . The $\mathrm{SH}$ total field intensity is presently higher than that of the NP. Comparison between the SH and NP intensities may suggest that the NP is in a process of displacement towards the SH (Mandea and Dormy 2003). From 1945 1950 to 1980 , intensities for the SH became slightly higher than those for the NP, but after 1980, the NP intensity began a rather rapid decrease, while the SH intensity became stable. 


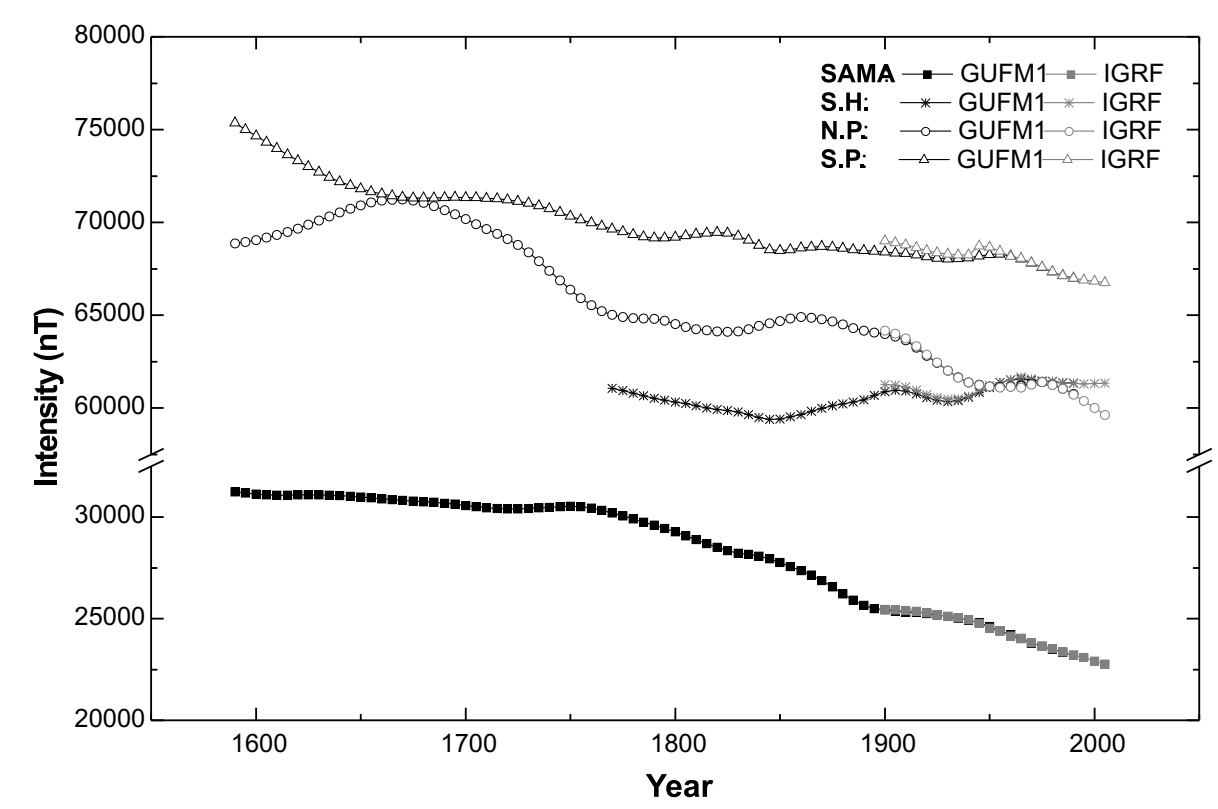

Fig. 7 - Total field intensity at the focus for SAMA, SH, NP, and SP from 1590 to 2005. The SH becomes apparent in after 1770 .

SAMA and other major features of the geomagnetic field, such as the poles (NP and SP), SH and non-dipole field anomalies, may be taken as "mobile observatories" since the use of the anomalies points of maximum or minimum may indicate field variations that are not evident when only observatory data and models are used.

The 1590-1750 period shows low SAMA variation rates and drift but, after 1750, time and space variations increase, and this coincides with the increase of nondipole sources and the appearance of SH around 1770. A correlation between the different phenomena is complex, but the phenomenology may be approached by using geodynamo concepts. Accurate geomagnetic field maps at the CMB show persistent reverse flux regions in the South Atlantic (e.g. Bloxham and Gubbins 1985, Bloxham 1987, Gubbins 1987, Gubbins and Bloxham 1987, Bloxham and Jackson 1989, 1992, Bloxham et al. 1989, Jackson et al. 2000, Olson and Amit 2006). Therefore, the SAMA observed at Earth's surface is related to CMB field morphology; in other words, SAMA seems to be a consequence of these reverse fluxes.

\section{CONCLUSIONS}

SAMA is a long-lived total intensity anomaly. Besides the usual westward drift, it has also had a predominantly southward drift with variable rates for the past 415 years.
The total field intensity at the anomaly center shows variable rates of decrease during this period. The space and time evolution of SAMA has been obtained with GUFM1 and IGRF models. Archaeomagnetic data indicate decay rates for the dipole moment that are lower than those for the present time and Gubbins et al. (2006) propose that the present decrease rate began around 1840 . However, in spite of GUFM1 models applying a $-15 n \mathrm{nT} /$ year linear extrapolation for $g_{1}^{0}$ for the period before 1840 (e.g. Barraclough 1974, Jackson et al. 2000), the obtained SAMA main characteristics such as drift, intensity variations, comparison with the non-dipolar field and with other anomalies seem to be quite coherent.

The SAMA influence is evident when intensities for observatories in the region (VSS, PIL, LAS e LQA) are compared. Decreases in total intensity indicate when SAMA was getting close. The change in intensity and direction for VSS after 1960 indicates how the SAMA center distance to this observatory increases. The effect of the increasing distance from the SAMA center to VSS is evident after approximately 1960 and supports the use of models for observing these anomalies. Figures display also an increase in the SAMA area of influence as indicated by the $28000 \mathrm{nT}$ contour lines. Therefore, the use of the minimum total field intensity seems to be adequate for our analysis. 
The analysis of the non-dipole geomagnetic field for the historical period shows that SAMA is an anomaly that is governed by quadrupolar and octupolar terms. The SAMA center drift (westward and southward) seems to be characterized by quadrupolar field. Intensity variation and area of influence is governed by quadrupolar and octupolar terms.

A comparison between the SAMA evolution and that of other major geomagnetic features may be helpful in predicting the future field, as for example in the hypothesis that the present field might be in the course of a reversion process (eg. Gubbins 1987), because presently the major geomagnetic features seem to equilibrate the total magnetic flux on Earth's surface in both hemispheres. However, a better understanding of this and other phenomena will be possible only with the progress of geomagnetic dynamo and CMB flux models.

\section{ACKNOWLEDGMENTS}

The authors thank Conselho Nacional de Desenvolvimento Científico e Tecnológico (CNPq), Coordenação de Aperfeiçoamento de Pessoal de Nível Superior (CAPES) and Fundação de Apoio à Pesquisa do Estado de São Paulo (FAPESP) (grant 2005/57782-4) for financial support to this work. They also thank two anonymous referees for their very helpful comments.

\section{RESUMO}

A Anomalia Magnética do Atlântico Sul (SAMA) é uma das maiores anomalias do campo geomagnético. A variação secular da SAMA foi obtida e comparada com a evolução de outras anomalias usando modelos de campo por harmônicos esféricos para o período de 1590-2005. Uma análise dos dados de quatro observatórios da América do Sul mostra como esta anomalia de grande escala afetou suas medidas. Como a SAMA é uma anomalia de campo total baixo, o campo foi separado nas componentes não-dipolar, quadrupolar e octupolar. A evolução temporal das razões dos campos não-dipolar/total, quadrupolar/total e octupolar/total mostram valores elevados para o Atlântico Sul desde 1750. A evolução da SAMA é comparada com a evolução de outras grandes feições geomagnéticas de superfície como os pólos Norte e Sul e o Alto da Sibéria, e sua comparação mostra o equilíbrio de intensidade entre estas anomalias em ambos os hemisférios. A análise dos campos não-dipolares no período histórico sugere que a SAMA é regida (i) pelo campo quadrupolar para a deriva, e (ii) pelos campos quadrupolar e octupolar para a intensidade e área de influência. Além disso, este estudo reforça a possibilidade de que a SAMA possa estar relacionada aos fluxos reversos no núcleo externo sob a região do Atlântico Sul.

Palavras-chave: campo geomagnético, anomalias do campo não-dipolar, variação secular, Anomalia Magnética do Atlântico Sul.

\section{REFERENCES}

BADHWAR GD. 1997. Drift rate of the South Atlantic Anomaly. J Geophys Res 102(A2): 2343-2349.

Badhwar GD, Atwell W, Reitz G, Beujean R and HEINRICH W. 2002. Radiation measurements on the Mir Orbital Station. Radiat Meas 35: 393-422.

Barde S, Cueto J, Ecoffet R, Falguère D, Nuns T, Duzellier S, Boscher D, Bourdarie S AND TsOuRILO I. 2002. Radiation Environment Measurements with SPICA On-Board the MIR Station. IEEE Trans Nuc Sci 49: 1333-1339.

BARRAClOUgh DR. 1974. Spherical Harmonic Analyses of the Geomagnetic Field for Eight Epochs between 1600 and 1910. Geophys J R Astron Soc 36: 497-513.

Bloxham J. 1987. Simultaneous Stochastic Inversion for Geomagnetic Main Field and Secular Variation 1. A Large-Scale Inverse Problem. J Geophys Res 92: 1159711608.

Bloxham J And GubBins D. 1985. The secular variation of Earth's magnetic field. Nature 317: 777-781.

BloXham J AND JACKSON A. 1989. Simultaneous Stochastic Inversion for Geomagnetic Main Field and Secular Variation 2. 1820-1980. J Geophys Res 94: $15753-$ 15769.

Bloxham J And Jackson A. 1992. Time-Dependent Mapping of the Magnetic Field at the Core-Mantle Boundary. J Geophys Res 97: 19537-19563.

Bloxham J, Gubbins D and Jackson A. 1989. Geomagnetic Secular Variation. Phil Trans R Soc London A 329: 415-502.

BONDI H AND GOLD T. 1950. On the generation of magnetism by fluid motion. Mon Not R Astron Soc 110: 607611.

BÜhler P, Zehnder A, Kruglanski M, Daly E And ADAMS L. 2002. The high-energy proton fluxes in the SAA observed with REM aboard the MIR Orbital Station. Radiat Meas 35: 489-497. 
Carlut J, Courtillot V and Hulot G. 1999. Over how much time should the geomagnetic field be averaged to obtain the mean paleomagnetic field? Terra Nova 11: 239-243.

Chapman S And Bartels J. 1940. Geomagnetism, vol 2. Oxford: University Press, 1049 p.

FIANDRINI E ET AL. 2004. Protons with kinetic energy E > $70 \mathrm{MeV}$ trapped in the Earth's radiation belts. J Geophys Res 109: A102014.

FrASER-SMITH AC. 1987. Centered and Eccentric Geomagnetic Dipoles and their Poles, 1600-1985. Rev Geophys 25: $1-16$

Glatzmaier GA And Roberts P H. 1995a. A threedimensional convective dynamo solution with rotating and finitely conducting inner core and mantle. Phys Earth Planet Int 91: 63-75.

Glatzmaier GA AND Roberts P H. 1995b. A threedimensional self-consistent computer simulation of a geomagnetic field reversal. Nature 377: 203-209.

GubBINS D. 1987. Mechanisms for geomagnetic polarity reversals. Nature 326: 167-169.

GubBins D And Bloxham J. 1987. Morphology of the geomagnetic field and implications for the geodynamo. Nature 325: 509-511.

Gubbins D, Jones A L And Finlay CC. 2006. Fall in Earth's Magnetic Field is Erratic. Science 312: 900-902.

Heirtzler JR. 2002. The Future of the South Atlantic Anomaly and implications for radiation damage in space. J Atmos Solar-Terr Phys 64: 1701-1708.

HEYNDERICKX D. 1996. Comparison between methods to compensate for the secular motion of the South Atlantic Anomaly. Radiat Meas 26: 369-373.

Hulot G, Eymin C, LANGais B, Mandea M and Olsen N. 2002. Small-scale structure of the geodynamo inferred from Oersted and Magsat satellite data. Nature 416:620 623.

JACKSON A. 2003. Intense flux spots on the surface of the Earth's core. Nature 424: 760-763.

JACKSON A, Jonkers ART AND WALKer M. 2000. Four centuries of geomagnetic secular variation from historical records. Phil Trans R Soc London A 358: 957-990.

Kageyama A And SATo T. 1997. Generation mechanism of dipole field by a magnetohydrodynamic dynamo. Phys Rev E 55: 4617-4626.

Kageyama A, Sato T and Complexity Simulation GROUP. 1995. Computer simulation of a magnetohydrodynamic dynamo II. Phys Plasmas 2: 1421-1431.
KUANG W and Bloxham J. 1999. Numerical modeling of magnetohydrodynamic convection in a rapidly rotating spherical shell: weak and strong field dynamo action. J Computational Phys 153: 51-81.

LANGEL RA. 1987. The main field. In: Geomagnetism, vol 1, cap 4. Edited by J A Jacobs, pp. 249-512, New York: Academic Press.

MandeA M AND Dormy E. 2003. Asymmetric behavior of magnetic dip poles. Earth Planets Space 55: 153-157.

OLSON P. 2002. The disappearing dipole. Nature 416: 591594.

Olson P And Amit H. 2006. Changes in earth's dipole. Naturwissenschaften 93: 519-542.

Pacca IG And Hartmann GA. 2005. The South Atlantic Magnetic Anomaly: Its Evolution and Relations with Other Anomalies on the Earth Surface and at the Core-Mantle Boundary. In: The IAGA Scientific Assembly, 2005, Toulouse, France.

Padilha A. 1995. Distortions in Magnetotelluric fields possibly due to ULF activity at the South Atlantic Magnetic Anomaly Region. J Geomag Geoelectr 47: 1311-1323.

Pinto JR O AND Gonzalez WD. 1986. X ray measurements at the South Atlantic Magnetic Anomaly. J Geophys Res 91(A6): 7072-7078.

Pinto JR O AND GonZALEZ WD. 1989. Energetic electron precipitation at the South Atlantic Magnetic Anomaly: a review. J Atmos Solar-Terr Phys 51(5): 351-365.

Pinto JR O, Gonzalez WD and GonZalez ALC. 1989. Time variations of X Ray fluxes at the South Atlantic Magnetic Anomaly in association with a strong geomagnetic storm. J Geophys Res 94(A12): 17275-17280.

Pinto Jr O, Gonzalez WD and Paes Leme NM. 1990. VLF disturbances at the South Atlantic Magnetic Anomaly following magnetic storms. Planet Space Sci 38(5): 633-636.

Pinto Jr O, Gonzalez WD, Pinto IRCA, Gonzalez ALC And Mendes JR O. 1992. The South Atlantic Magnetic Anomaly: three decades of research. J Atmos Solar-Terr Phys 54: 1129-1134.

Pinto Jr O, Mendes O, Pinto IRCA, Gonzalez WD, Holzworth RH AND HU H. 1997. Atmospheric Xrays in the Southern hemisphere. J Atmos Solar-Terr Phys 59(12): 1381-1390.

Pinto LMVG, SzcupaK J, DRUMmond MA ANd MaceDO LH. 2004. A new look on safety of electric systems. Reports Engenho Pesquisa: 1-6. 
Roberts PH and Glatzmaier GA. 2000. Geodynamo theory and simulations. Rev Modern Phys 72: 1081-1123.

Trivedi NB, PAThan BM, Schuch NJ, Barreto LM AND DUtRA LG. 2005. Geomagnetic phenomena in the South Atlantic anomaly region in Brazil. Adv Space Res 36: 2021-2024.

Willis P, Haines B, Berthias JP, Sengenes P AND LE MOUËL JL. 2004. Comportement de l'oscillateur DORIS/Jason au passage de l'anomalie sud-atlantique. CR Geoscience 336: 839-846.
YUKUTAKE T AND TACHINAKA H. 1968. The non-dipole part of the Earth's magnetic field. Bull Earth Res Inst Univ Tokyo 46: 1027-1074.

YUKUTAKE T AND TACHINAKA H. 1969. Separation of the Earth's magnetic field into the drifting and the standing parts. Bull Earth Res Inst Univ Tokyo 47: 65-97. 